\title{
A CINCUENTA AÑOS DEL MOVIMIENTO ESTUDIANTIL Y POPULAR DE 1967 EN SONORA
}

Resumen. Próximamente se cumplirán cincuenta años del movimiento social más importante de la segunda mitad del siglo XX en Sonora: el movimiento estudiantil y popular de 1967. Así como se afirma que México fue otro después del movimiento estudiantil y popular de 1968, se puede decir que Sonora tuvo su parteaguas en el '67 y comenzó a cambiar; también que los sucesos de ese año en Sonora fueron un antecedente directo de lo que ocurriría un año después en el Valle de México. En el presente artículo, de manera sintética, presentamos los principales acontecimientos del movimiento y anotamos una explicación. Tomamos como base del artículo el apartado referido al tema en la tesis de doctorado Cambio y continuidad institucional en la historia de la Universidad de Sonora: 1938-1982, presentada en diciembre del 2014 en el Colegio de Sonora. Como comprobarán, el movimiento estudiantil y popular de 1967 fue muy importante pero es poco conocido fuera de las fronteras estatales, aunque tiene lecciones que las trascienden claramente. Vale la pena entonces hacer un balance del mismo a los cincuenta años de ocurrido para un público diferente.

Palabras clave: Movimientos sociales, actores políticos, movimiento estudiantil.

\footnotetext{
${ }^{1}$ Doctor en Ciencias sociales por el Colegio de Sonora. Maestro de tiempo Completo en el Departamento de Economía de la Universidad de Sonora. Presidente de la Academia de Historia y Desarrollo Sustentable. Coordinador de la Maestría en Comercio Exterior y Aduanas de la propia Universidad de Sonora. Correo: amorenos@guaymas.uson.mx.
} 


\section{El inicio y los antecedentes}

Fue en el contexto de elección de gobernador y teniendo como antecedente lo ocurrido seis años antes, que se iniciaron los acontecimientos que marcarían una época.

En 1961 se llevó a cabo un "experimento democrático" para elegir gobernador, una “excepción" en el calendario y en la vida política nacional, en el cual a decir de uno de los contendientes y finalmente vencedor: "tanto mi adversario político como yo, fuimos llamados y autorizados por el presidente del PRI para realizar trabajos y siempre fijándosenos algunas condiciones y limitaciones" (Encinas 1969, 32). Se trataba del Lic. Luis Encinas Johnson, rector de la Universidad de Sonora, quien en marzo de ese año había solicitado licencia durante dos meses; después otros dos y no volvería a rectoría, pues se embarcó en la aventura y salió triunfador.

El adversario era el Lic. Fausto Acosta Romo. Según la mayoría de las fuentes, los dados estaban cargados a favor de él; incluso la central campesina del PRI (CNC) le había comprometido su apoyo. Finalmente Encinas ganó la nominación; jugó a su favor el que Acosta Romo no cumpliera con lo dispuesto en el Artículo 37 de la Constitución local: seis meses de residencia efectiva en el estado antes de las elecciones del primer domingo de julio; además de las relaciones que había establecido desde rectoría ${ }^{2}$, especialmente con el presidente de la república (Moncada 2007: 57).

Teniendo como antecedente lo ocurrido en 1961, el periódico más importante en el estado, El Imparcial, estuvo empujando a una definición democrática dentro del Partido

\footnotetext{
${ }^{2}$ A decir de Moncada, “en los primeros seis meses de 1960, Luis Encinas había tenido dos audiencias con el presidente y había sido su anfitrión en la Universidad dos días consecutivos... en el transcurso de 1960 había recibido en la Universidad, por diversos motivos, a los secretarios de Educación Pública, Jaime Torres Bodet; de Agricultura y Ganadería, Julián Rodríguez Adame; de Comunicaciones y Transportes, Walter Buchanan, y de Obras Públicas, Javier Barros Sierra, así como al secretario general de la Confederación Nacional Campesina, profesor Francisco Hernández y Hernández”.
} 
Revolucionario Institucional (PRI) y con precandidato preferido. Por ejemplo, Enguerrando Tapia, entonces columnista muy influyente del mismo, escribía en "Mi Libreta de Apuntes" a fines de 1966, “el pueblo sonorense participará en los sucesos con calor y con valentía... Nada de cuentos ni de 'dedazos' a la antigüita... Al contrario, la democracia en marcha bajo el amparo de la Constitución General de la República, de la Constitución del Estado Libre y Soberano de Sonora, y de las garantías de un régimen nacido de la Revolución Mexicana representada por Gustavo Díaz Ordaz (El Imparcial, 3/12/1966: 3). Y es que dicho diario y el grupo que estaba detrás tenía su candidato, en solemne editorial el 29 de diciembre había expresado, "en esta fecha precisamente queremos dejar bien establecido que de los aspirantes expuestos ante la opinión pública, ¡El Imparcial”, se inclina por el señor Enrique Cubillas” (El Imparcial, 29/12/1966:1).

¡Estamos contigo!, versus ¡firmes a tu regreso! Enrique Cubillas, (E.C.: estamos contigo), entonces presidente de la Unión Ganadera Regional de Sonora (URGS), se encontraba en diciembre en abierta campaña de proselitismo, abriendo comités, incorporando personalidades. Se decía también que tenía la anuencia del Presidente Nacional del PRI, Lauro Ortega, de quien era amigo personal. El siguiente precandidato que saltó a la palestra era el precandidato derrotado en 1961, Fausto Acosta Romo (F.A.R.: firmes a tu regreso) que había renunciado a la Subprocuraduría "A” de la República por venírsela a jugar a Sonora, y cumplir con el requisito de seis meses de residencia efectiva que preveía la constitución local. El destape del mismo fue el 22 de diciembre de 1966 en el despacho del licenciado Jesús Enríquez Burgos, con la presencia, entre otros, de los empresarios Pedro Valenzuela, Luis Salcido, Enrique Tapia, Emiliano Corella y el político, Raúl Encinas Alcántar (El Sonorense, 23/12/1966:1). Llegó a la ciudad capital el día último del año siendo recibido en el Casino de Hermosillo, donde dijo, “Atendiendo la invitación de numerosos ciudadanos y amigos del Estado, para participar en los actos cívicos que habrá de realizar en Sonora el Partido Revolucionario Institucional en $1967 \ldots$., con el propósito inmediato de restablecer mi 
residencia en mi querida tierra sonorense, cumpliendo con el artículo 37 de la constitución local” (El Imparcial, 31/12/1966: 1; El Sonorense, 1/01/1967: 1).

Además de estos dos candidatos se mencionaban a otros como César Gándara, el Ing. Leandro Soto Galindo que el día 9 de febrero fue destapado por su coordinador de campaña el Lic. y columnista Rafael Vidales Tamayo. En su comité andaba entre otros el Ing. Luis Robles Linares.

El que se mueve no sale en la fotografía. Naturalmente, el PRI local había descalificado la labor de proselitismo abierto de los dos primeros precandidatos, lo había hecho en Nogales el 8 de diciembre (El Sonorense, 9/12/1966:1). Y el PRI Nacional había expresado el 27 de diciembre, "No será hasta fines del mes de febrero o mediados de marzo cuando el Comité Ejecutivo Nacional resuelva en forma simultánea quiénes son sus candidatos" (El Sonorense, 28/12/1966:1). El 6 de enero el sempiterno líder de la CTM había afirmado, "la CTM no está favor ni en contra de los precandidatos, sino que únicamente espera actuar según los lineamientos del PRI “(El Sonorense, 7/01/1967: 1). El mismo Lauro Ortega, desde la Ciudad de México también había buscado detener el proselitismo abierto, "toda elección tiene su fecha y cuando el Comité Ejecutivo Nacional del PRI lo considere oportuno, lanzará las convocatorias para que los ciudadanos que aspiren a puestos de elección popular, inicien las actividades correspondientes" (El Sonorense, 10/01/1967:1): En ese mismo sentido, la CTM publicaba manifiestos (El Sonorense, 10/1/1967: 2; El Imparcial, 12/01/1967:3).

Sin embargo, ni estas ni otras señales inhibían la actividad de los simpatizantes de Enrique Cubillas ni de Fausto Acosta Romo.

¡El sabadazo! Finalmente el sábado 18 de febrero de 1967, después de más de mes y medio de campaña abierta por los mencionados precandidatos, el partido "destapa" a Faustino Félix Serna, quien no se había movido para salir en la fotografía. El Sonorense a 8 columnas 
anunciaba, "dio su apoyo decidido la CTM al diputado Federal Faustino Félix Serna", en la cachucha, "el continuismo Faustinista", y en el cintillo, "No más titubeos, afirman".

Faustino Félix Serna, era un rico empresario y político que había nacido en Átil pero se había desarrollado en el sur del Estado, concretamente en Ciudad Obregón, donde se había dedicado a la agricultura, ganadería, empresas transportistas y la política. Había sido el Jefe de Campaña de Luis Encinas en 1961, no queriendo ser secretario de Gobierno por ser quien ocupa ese cargo "gato del gobernador", se había desempeñado como presidente municipal de Cajeme (1961-1964) y diputado federal (1964-1967). Lo apoyaban fuertes capitales del sur del Estado, la CTM, el Secretario de gobernación, Luis Echeverría, (en ese sentido se considera un triunfo de él en su carrera a la presidencia la final imposición de Faustino) y, claro, del gran elector de ese momento, el presidente, Gustavo Díaz Ordaz.

Sin embargo, el destape del "sabadazo" como lo mencionaban, no era oficial, incluso la convocatoria no había sido publicada, y tuvo la virtud de acelerar los acontecimientos. El día 21, El Imparcial reproducía unas declaraciones de Fidel Velázquez en la prensa nacional donde afirmaba que "su central no apoyaba a nadie para candidato a gobernador, tampoco en Sonora. Las organizaciones sonorenses que han respaldado a Faustino Félix Serna, son agrupaciones locales, el apoyo que cuenta es el del Comité Ejecutivo Nacional de la CTM, que seguirá las directrices de Nuestro Partido". Para acabar de complicar la situación comienzan a aparecer desmentidos al apoyo de Faustino Félix. El domingo 19 se publica en El Imparcial un desplegado firmado por Pedro Díaz Godoy, Secretario de Organización de la Federación Hermosillense de la CTM; Francisco Leyva Duarte, Secretario General del Sindicato de Electricistas; Enrique García, Secretario de Promoción Industrial de la Federación Local; Roberto Zambada Félix, de la Unión de Permisionarios de ruleteros, también desmentirían el apoyo, la Asociación de Arquitectos de Ciudad Obregón y Ernesto Molina, Secretario General de Sindicato de Pequeños Propietarios de Automóvil de Ímuris, entre otros. En ese mismo sentido, un boletín del PRI nacional y reproducido aquí, afirmaba, 
“será hasta que regresen el señor Lauro Ortega y los representantes de los tres sectores, cuando el PRI estudie y resuelva el caso Sonora. (El Imparcial, 21/02/1967: 1).

Por otra parte, el destape de Faustino aceleró la movilización, especialmente de los que apoyaban a Acosta Romo. El mismo sábado en la mañana en un mitin en el Cine Reforma, el precandidato habló ante 5 mil personas y se formó el Centro Director de los Trabajos Acostarromistas, destacando entre sus dirigentes el Lic. Alfonso Castellanos Idiáquez, quien después sería rector de la Universidad de Sonora, el Lic. Abraham F: Aguayo, también maestro de Derecho y el empresario Pedro Valenzuela. A partir de entonces se dedica a recorrer el estado movilizando a sus simpatizantes: el lunes 20 se encuentra en Guaymas, al día siguiente en Ciudad Obregón donde llena a reventar la Arena Coliseo. Ese mismo día recibe el respaldo de jóvenes estudiantes y profesionistas a través de un desplegado en donde destacaban: Óscar Cárdenas Verdugo, Héctor Dena Luna, Roberto Sánchez Cerezo, Miguel Ángel Bustamante, Santiago Cota de la Torre, Bernardo Cabrera Lemas, Jesús Torres Gallegos, Víctor Valencia Núñez, Oscar Téllez Ulloa, Alán Sotelo Cruz, Francisco Soto Figueroa, Jorge Amaya Acedo, Ignacio Bussani, José Antonio Dávila Payán, entre otros. Varios de ellos tuvieron activa participación en la huelga universitaria. El miércoles 22 realiza un mitin en Navojoa donde fue orador quien con el tiempo sería gobernador del estado, el Dr. Samuel Ocaña García (1979-1985). Cancela los mítines programados en Huatabampo y Bacobampo y sale intempestivamente a la Ciudad de México.

Oficial, Faustino Félix Serna el precandidato del PRI. Finalmente, el jueves 23 de febrero de 1967, se publica en la prensa Nacional y en El Sonorense, "La confederación de Trabajadores de México apoya plenamente la precandidatura de Faustino Félix Serna para gobernador de Sonora" (El Sonorense, 23/02/1967:1). Ese mismo día llegaba con la convocatoria el delegado especial del PRI el entonces Senador, Bernardo Quintana, quien de paso dio el espaldarazo a Faustino. Ante el respaldo de los tres sectores del PRI a dicha 
precandidatura, otros de los aspirantes comienzan a renunciar; lo hace César Gándara, desde la Ciudad de México, Armando Hopkins Durazo, Armando Reyna Celaya.

¡Faustino no! Sin embargo, a diferencia de otras ocasiones y circunstancias la movilización social en lugar de decaer se incrementa. El viernes 24 en una manifestación de Acostarromistas a la que se sumaron los Sotogalindistas apareció el famoso "Faustino No" en los aproximadamente 2 mil carros y unas 10 mil personas de a pie que, según El Imparcial (25/07/1967:1), habían participado en la movilización. El sábado 25, un denominado Frente Unido de Defensa de la Dignidad, el Deber y la Responsabilidad Cívica invitaba a manifestarse a diario en "desaprobación a los procedimientos y métodos adoptados, para que nuestro Partido Revolucionario Institucional designe su candidato a la gubernatura del Estado" (El Imparcial, 25/02/1967:1). Ese día en la mañana y tarde se realizaron manifestaciones. La de la tarde fue en automóvil que El Sonorense calificó de "escandaloso desfile" de "acaudaladas familias de la ciudad" (El Sonorense, 25/07/1967:12). A decir de El Imparcial se habían realizado actos contra la imposición en Nogales, Ciudad Obregón, San Luis Río Colorado y Cananea.

Como, para el domingo 26, se tenían contemplados dos mítines uno de la oposición frente al Museo y Biblioteca de la Universidad y, el otro, frente a la Casa de Campaña de Faustino (en su local contiguo al Restaurante Las Cazuelas, donde hoy se encuentran las oficinas de Telmex) distantes unas 4 cuadras uno del otro. Ante esa situación el secretario de Gobierno, Cesar Tapia Quijada, reunió al presidente municipal, Alberto Gutiérrez, y los representantes de Faustino Félix, Fausto Acosta, Enrique Cubillas y Leandro Soto Galindo.

La violación a la autonomía universitaria. A pesar de los buenos oficios del Secretario de Gobierno el domingo 26 de febrero se realizaron ambos actos. La oposición se comenzó a reunir desde las 10 de la mañana. Faustino trajo gente del sur del Estado y de Sinaloa que se identificaban por sombreros y cintas verdes por lo que comenzaron a ser llamados la "ola 
verde". Pronto los contingentes de ambos actos comenzaron a enfrentarse, piedras y contingentes iban y venían, varios automóviles fueron incendiados. En el mitin del precandidato oficial tomaron la palabra: Nicolás Rocha (CTM), Pedro Rosas (CTS-CROC), Ignacio Guzmán (CNC Nacional), Dr. Alfredo Chacón Madrid (Trabajadores IMSS estatal), Javier Robinson Bours (Empresario), Blanca Irene Avilés (Sector Femenil) y, José Tinajero Meza (estudiante). Cuando el precandidato iba tomar la palabra un carro a toda velocidad fue lanzado contra la multitud con lo que el mitin terminó abruptamente. La policía después de estar a la expectativa durante unas horas, finalmente interviene. La municipal arremete contra la oposición que corre a refugiarse en la Universidad, la policía tras ellos entra a la Universidad violando la autonomía (El Pueblo: 27/02/1967:8). Al día siguiente la Federación de Estudiantes de la Universidad de Sonora (FEUS) se involucra por primera vez en el conflicto convocando a una manifestación "muda", El Sonorense (28/02/1967: 1 y 6) la calificó de "ejemplar y ordenada", que salió a las 18:30 horas de la Universidad con rumbo al palacio de gobierno donde se entrevistaron con el gobernador, Luis Encinas, a quien le exigieron la destitución del Comandante de la Policía Judicial del Estado, Capitán Francisco Cifuentes, y, el jefe de la policía municipal, mayor Francisco Luken Aguilar "Pancholín". En esa ocasión, a decir de El Sonorense (28/02/1967:1), había declarado, "al igual que ayer y hoy, mañana, cuando entregue el poder, seguiré siendo un soldado de la autonomía universitaria", días después, el $1^{\circ}$ de marzo ambos funcionarios policiacos renunciaron. Parecía que el conflicto estaba resuelto. Cuantimás que los dos candidatos opositores más importantes renunciaban a las precandidaturas: desde la Ciudad de México, Enrique Cubillas, mediante un boletín donde el ganadero Manuel Torres informaba que el comité dejaba de funcionar (El Imparcial, 26/02/1967:1) y, Fausto Acosta Romo, dos días después (El Imparcial 28/02/1967;3), ante las dudas lo ratificó el día 1 de marzo (El Sonorense y El Pueblo) y el 11 de marzo, “....solicítole confirmar mi decisión de retirarme de la campaña preelectoral... Reitero a mis compañeros y amigos, mi recomendación de mantener la unidad 
de nuestro partido...., disciplinándose a la selección hecha ya por los tres sectores de nuestro Instituto Político" (El Sonorense, 12/03/1967:1 y 12).

La llama no se extingue. Entre los acontecimientos del domingo 26 de febrero, que provocó la violación de la autonomía, la renuncia de los jefes policiacos y de los precandidatos de oposición y, la convención estatal del PRI, donde se nombraría oficialmente a su candidato, mediaba un mes, se realizaría el 26 de marzo. Mientras el precandidato oficial se dedicaba a despachar en sus oficinas en Hermosillo donde recibía a empresarios y políticos, parecía que los acontecimientos se desarrollarían por los cauces normales, sin embargo, "la burla de que habría sido objeto el pueblo sonorense había encendido un fuego que no tan fácilmente sería apagado. La mayoría de la gente ingenuamente había creído que el candidato del PRI sería elegido democráticamente, se encontraron con una decisión vertical, desde arriba, desde la Presidencia. Esperaban que por lo menos la democracia dentro del partido oficial se respetaría y se encontraron con una decisión, desde arriba e impopular. Por otra parte, la precampaña había incentivado a fuertes intereses. La burguesía que había apoyado a Enrique Cubillas o a Fausto Acosta Romo, resentida, estaba dispuesta a apoyar el descontento, poseían armas suficientes, una de ellas la influencia que tenían en la universidad a través del Patronato. Además, no sólo la burguesía inconforme estaba lista a pelear, lo primero era tratar de cambiar la dirección (Moreno 1983: 27/09:4). En ese sentido el día 3 de marzo, a decir de El Imparcial, 150 estudiantes formaron el Frente Estudiantil Universitario AntiImposicionista (FEAI). Entre los participantes destacaban: Gustavo Reyes, Lupita Mendívil, Adán Maldonado, Rita Chávez, Concepción Riesgo, Agustín Caballero Gutiérrez, Miguel Ángel Castellanos, Álvaro Villagrán Ochoa y Víctor Alcaraz. Sus principios eran: ser independientes de la FEUS y cualquier Sociedad de Alumnos, no apoyaba a ningún precandidato, oponerse a cualquier humillación y afrenta al pueblo de Sonora, se integra por universitarios, apoyar al pueblo Sonorense ante la imposición en cualquier puesto de elección popular (El Pueblo 6/03/1967:1 y 8). El mismo día en que se dio a conocer la formación del 
FEAI, salió un desplegado firmado por el presidente de la FEUS, Horacio Risk Molinar, y varios presidentes de sociedades de alumnos, donde bajo el título de "Yo Acuso" a los estudiantes, Alejandro Sánchez Meza, Milton Castellanos, Roberto Sánchez Cerezo, Marco Antonio Murillo, Gustavo López Escalante, Enrique Mendoza, Adán Maldonado, Luis Felipe Pavlovich, Tomás Cid Lucero, y Alberto Castro Salido, de involucrar a la Universidad en movimientos políticos ajenos a la misma (El Sonorense, 5/03/1967: 6).

Al día siguiente, la FEUS realizó una asamblea general en el Auditorio del Museo y Biblioteca donde, ante la imposibilidad del presidente de la FEUS de demostrar sus acusaciones y "en vista de que había perdido la autoridad moral y la confianza del estudiantado" fue removido entrando un sustituto. Las elecciones para nuevo presidente de la FEUS se llevaron a cabo los días 14 y 15 de marzo, siendo ganador el estudiante del tercer semestre de la Escuela de Agricultura y Ganadería, Hilario Valenzuela Corrales, el 16 tomó posesión.

Estalla la violencia. Si al interior de la Universidad seguían las manifestaciones de inconformidad y se llevaba a cabo una redefinición, al exterior los simpatizantes de Acosta Romo y Cubillas, así como los Soto Galindo que no se habían retirado de la contienda, hacían mítines casi diario en el Jardín Juárez y frente al Museo y Biblioteca, además de volanteo, y publicaciones de desplegados. El día 12, mientras Faustino realizaba un mitin en Ciudad Obregón, Leandro Soto lo llevaba a cabo enfrente del Museo. Esa noche la carpa que el FEAI tenía en las confluencias del transversal y Rosales es agredida y quemada. El domingo 19 de marzo el FEAI estalló una huelga de hambre en la plaza Zaragoza. Además organizaron una manifestación del Jardín Juárez a la misma plaza Zaragoza pasando por la Matamoros, Transversal y Rosales, al pasar en esta última avenida por el local de Faustino se volvió a vivir un enfrentamiento con saldo de varios heridos (El Sonorense, 20/03/1967:1 y 2). Al día siguiente en la madrugada los huelguistas de hambre son agredidos. A partir de entonces, a 
decir de Rafael Delgado (Life en Español, 27/05/1967:27), “empezó un período de 72 horas de violencia".

Aunque por todos los barrios de Hermosillo, se escuchaban disparos y, según el FEAI tres personas habían sucumbido, el lunes 20 el gobernador informó que nadie había muerto en el tiroteo. Al día siguiente, los Felixistas dijeron que uno de sus compañeros había recibido un balazo mortal".

Para entonces el 15 de marzo la Confederación Nacional Campesina (CNC) había elegido a Faustino Félix como su candidato no sin problemas.

El día 21, en el Cine Sonora, en Hermosillo se realizó la Convención de la Confederación Nacional de Organizaciones Populares (CNOP) que en menos de una hora eligió a Faustino como su candidato, mientras en las calles aledañas estallaba de nuevo la violencia que se extendió por todo el centro de la ciudad, llegó hasta el local faustinista y el restaurante Las Cazuelas fue quemado. Por esos acontecimientos renunciaron el presidente Municipal, Alberto Gutiérrez y su Secretario, Ramiro Dávila Meléndrez.

Por entonces se supo de las importaciones que el gobernador había hecho de gases lacrimógenos y otros instrumentos de represión que abonaron a su descrédito.

El 24 se realizó la Asamblea Estatal de la CTM con la presencia de los dirigentes a nivel estatal y nacional e igual, no sin problemas. Y, finalmente, el domingo 26 de marzo se llevó a cabo la Convención Estatal del PRI de donde surgiría Faustino Félix como candidato oficial, "dentro de una zona de Estado de sitio"(El Pueblo, 27/04/1967:1). Abelardo Casanova (El Imparcial, 28/03/1967:6), sintetizaba así el ambiente por aquellos días, "por mucho que quisiera hacérsele al jilguero, no puede ocultarse que todo este asunto de selección del candidato del PRI ha dejado en el pueblo sonorense un sabor amargo y un ánimo sombrío; la ola verde, la dispersión a balazos de los huelguistas, el chequeo de ciudadanos, y el 
'fichamiento indiscriminado' de aprehendidos en las calles, no podrán ser olvidados por mucho tiempo por los sonorenses".

La Huelga universitaria. Un día después de la Convención Estatal del PRI donde FFS es nombrado candidato oficial, el 27 de marzo, también primer día de clases después de las de Semana Santa durante la cual la plenaria sin vacaciones estuvo elaborando el pliego petitorio, la FEUS publicó un desplegado que apareció en los periódicos un día después, donde pedían castigo para los autores intelectuales y materiales de la inestabilidad y el caos y que mientras se “cumpla su petición permanecerían acantonados". Dos días después, el miércoles 29 de marzo durante la mañana, se reunieron alrededor de 3 mil estudiantes y determinaron estallar la huelga a las 12:00 horas.

El pliego petitorio.

Exigían la renuncia del gobernador, acusándolo de:

1) Violación a las garantías individuales: al impedir reuniones públicas pacíficas y la entrada a Hermosillo a contingentes que venían a participar en actos de esta localidad, al ser molestadas muchas gentes en su persona y en su domicilio, sin que mediara mandamiento escrito de autoridad competente. La detención de cientos de personas sin orden de aprehensión, arrestos domiciliarios, sin órdenes de cateo y los golpes y vejaciones a que eran sometidos los arrestados.

2) Infracción a las leyes federales causando prejuicios graves al estado de Sonora y motivando trastornos en el funcionamiento normal de las instituciones. Delito previsto en la misma ley de responsabilidades, cometido por la actuación de la policía y por haberse armado a civiles (la ola verde) que provocaron desórdenes. 
3) Usurpación de atribuciones: delito descrito en la misma ley de responsabilidades y que se configuró al importar el gobierno de Sonora armamento cosa que solo puede hacer la Secretaría de la Defensa Nacional.

4) Omisiones de Carácter grave al permitir el funcionamiento de la ola verde. (Mercado; 1973:10-15).

Los miembros de la plenaria de la FEUS, es decir la asamblea de presidentes de sociedades de alumnos, estaba compuesta por: Jesús Larios Gaxiola, Ingeniería Civil; Alberto Castro Salido, Derecho; Jorge Lebrún Almada, Ciencias Químicas; Rubén Pablos Soto, Contabilidad y Administración; Javier Siqueiros, Agricultura y Ganadería; Hilda Benítez Carrión, Trabajo Social; Clementina Ortiz, Enfermería; Abraham Velazco, Preparatoria Central Diurna; Alonso Durazo, Preparatoria Nocturna; Leonel Arguelles Méndez, Preparatoria de Navojoa; Luis Donaldo Colosio Murrieta, Preparatoria de Magdalena; Max Gutiérrez Cohen, Secundaria de la Universidad.

Mover la palmera para que caiga el chango. Dado que oficialmente Faustino Félix era el candidato del Partido del Estado pero no se había registrado aún ante las autoridades electorales, se cambió de estrategia que se sintetizó en la frase. "mover la palmera para que caiga el chango", es decir, mover o tumbar al gobierno estatal para que cayera el candidato.

Al estallar la huelga en la Universidad se formaron varias comisiones: abastecimientos, orden, finanzas, exterior, prensa y propaganda, organización, Interior, sonido y jurídico. (Mercado 1973, 15) En ese sentido a partir de entonces se concatenan dos actividades, la organización interna de la huelga y, al exterior para pedir la solidaridad y ampliar el movimiento.

Al interior el acantonamiento, las brigadas de seguridad, y las guardias nocturnas, la formación de brigadas de volanteo y boteo, las cafeterías convertidas en comedores 
colectivos atendidos por compañeras estudiantes, de acuerdo a la división del trabajo según sexo bien establecida entonces.

\section{De huelga universitaria a huelga del sistema educativo, de movimiento estudiantil a} popular. Por otra parte, pronto salieron las brigadas a las distintas poblaciones del Estado buscando solidaridad y la extensión de la huelga. Para sorpresa de todos, incluyendo a los estudiantes, el movimiento se extiende con inusitada rapidez. El mismo día que estalla la huelga en la Universidad de Sonora paralizan actividades en la Normal del Estado. Al día siguiente, 30 de marzo, lo hacía la Escuela Nocturna Ángel Arreola. Pronto la movilización traspasó la educación media y media superior abarcando las primarias, como decía Casanova, “al extenderse la huelga hacia fuera de la Unison, el filo de la navaja se traslada ahora a las escuelas primarias; por un lado, los padres que apoyan el movimiento no se limitan a retener a sus hijos para que no asistan a la escuela, sino que se presentan en ella con bandera y todo lo demás” (El Imparcial, 8/04/1967:7). Es decir, en las primarias eran las propias Sociedades de Padres quienes declaraban la huelga y se acantonaban. Ya para el 6 de abril, a decir de El Imparcial, "en Hermosillo, no hay clases en casi todos los planteles del Estado", ese mismo día la preparatoria privada y lasallista del Regis entraba en suspensión de actividades. En un paro programado para el 14 de abril de 11 a 12 horas según el mismo medio estuvieron “involucrados 131 escuelas, 70 mil alumnos y 50 negocios comerciales de Hermosillo. (El Imparcial, 15/04/1967:1). Entre los días 17 y 21 de abril la casi totalidad del sistema educativo público, desde la Universidad a las primarias, estaban en huelga.

Pero no sólo en el sistema educativo se manifestaba la inconformidad. El 12 de abril, entre 8:00 y 9:00 horas, paralizaron actividades Mazón Hermanos, Mexsuiza, Almacenes García. El 13, el 90\% del comercio hermosillense paró de 11:00 a 12:00 horas, el 15 de 8:00 a 12:00 y, el 21 de 14:30 a 18:30 horas. Al unísono los mítines, caravanas y manifestaciones multitudinarias se realizaban no sólo en Hermosillo sino en todo el estado. Otra medida 
significativa fue huelga de hambre que se inició el 12 de abril en la plaza Zaragoza y que fue replicada en Empalme, Guaymas, Ciudad Obregón y Navojoa, la misma se levantaría, 11 días después, el 23 de abril. El día 21 de abril, fecha donde se conmemoraba el día del estudiante se llevó a cabo un paro general con huelga de hambre general.

El 18 de abril el rector y los directores de las escuelas publican un desplegado, donde daban a conocer que se suspendían todas las actividades institucionales, hasta que "el orden académico se vea (...) plenamente restablecido o hasta la época de nuevas inscripciones para el próximo año escolar" (El Sonorense; 18/04/1967: 1 y 6).

Ante el control que el Estado tenía de las organizaciones sociales, es clave para la expansión del movimiento la solidaridad y el compromiso de los padres de familia y de los maestros, especialmente los pertenecientes al sistema estatal. Desde el $1^{\circ}$ de abril 11 sociedades de padres de familia habían dado su apoyo a la FEUS (El Imparcial, 2/04/1967: 1). A pesar de la presión de la Dirección General de Educación en el Estado (El Sonorense 4/04/1967:1) el proceso siguió adelante. Los maestros por su parte, tanto de la sección 54 como la 28, conformaron el Frente Magisterial de Defensa Cívica el 10 de abril en la Normal del Estado, destacarían entre los líderes José Velarde y Manuel Ríos Ríos (en realidad Manuel Ríos Romero). La FEUS, el Frente Magisterial y las Sociedades de Padres de Familia formaron finalmente el Bloque Cívico del Pueblo (B.C.P).

Además de las anteriores manifestaron su solidaridad con el movimiento: la Escuela de Filosofía y Letras de la UNAM, "un grupo de muristas agredió a varios estudiantes y profesores de la Facultad de Filosofía y Letras que realizaban un paro de 24 horas en apoyo a las universidades de Sonora y Tabasco" (Rivas, 2007: 397), la Escuela de Agricultura de la Universidad Autónoma de Sinaloa, Estudiantes de la Universidad Autónoma de Baja California, la Sección Local del Sindicato Nacional de la Industria Textil y Similares de la República Mexicana, La Unión General de Obreros y Campesinos de México (UGOCM), las 
secciones 6 y 43 del Sindicato Nacional de la Industria del Cemento, Cal, Yeso y sus productos similares y Conexos de la República Mexicana, la Federación de Trabajadores al Servicio del Estado, (FSTE) que demanda el apoyo que sus dirigentes (encabezados por Moisés "cuervito" Zamora) había brindado a Luis Encinas, las Sociedades de Crédito de la Industria de Sonora, la OTS-CROC, el Centro Cívico y Renovador del PRI, el Centro Patronal del Norte de Sonora, la Asociación de Agricultura del Norte de Sonora, la CANACO de Hermosillo, la CANACINTRA del Estado de Sonora (Que provocó desmentido de nueve subdelegaciones) (El Sonorense 11/04/1967:4)

El Estado de Sonora dividido. El gobernador Luis Encinas recibía, en cambio, el apoyo de la CTM y CNC con sendos desplegados el 1 de abril, del Secretario General de CTS-CROC y un grupo de burócratas encabezados por Moisés “cuervito" Zamora, La Junta Coordinadora de la Iniciativa Privada de Navojoa, la Cámara Nacional de Comercio del Mayo, la Unión de Crédito Agrícola del Mayo, el Comité Ejecutivo de la Sección 65 de Cananea, los Comerciantes de Cajeme, grupo de Campesinos del Yaqui, el 12 de abril se publicaba un manifiesto firmado por la CANACO y la CANACINTRA de Guaymas, la Cámara Nacional de la Industria Pesquera, la CNC y la CNOP de Guaymas (El Sonorense, 12/04/1967: 1 y 2).

Como puede verse la participación en el movimiento es amplia, a favor y en contra, el estado y la Iniciativa Privada dividida entre sur y norte, aunque es sintomático que no aparece entre los apoyos al gobernador los empresarios de Cajeme.

Durante ese período donde el candidato oficial, pero todavía no registrado ante las autoridades electorales, hace labor de proselitismo, recibiendo comisiones, recorriendo el estado, con momentos tensos. Y, la oposición buscando "mover la palmera para que caiga el chango", se dieron dos enfrentamientos, el 11 de abril cuando la policía tomó el ITSON, y el 17, al ser agredidos los padres de familia de la Escuela Gral. A. Rosales de Navojoa por parte 
de la ola verde. Una opositora al movimiento con mucha presencia fue la Federación de Sociedades de Padres de Familia del Valle del Yaqui fundada el 20 de abril, que, ese mismo día, impedía estallara la suspensión de labores en la Escuela Adalberto Salcido, y comenzaran a recorrer el Valle del Yaqui (El Sonorense, 21/04/1967: 1 y 6).

Gustavo Díaz Ordaz. Al estilo de la época, la oposición a Faustino y que buscaban la destitución de Luis Encinas, clamaban por la intervención del Presidente de la República, a quien suponían mal informado. Habían buscado con ahincó la entrevista siendo siempre derivados hacia el secretario de gobernación. Por fin el 24 de abril en Mexicali, durante 45 minutos, Gustavo Díaz Ordaz recibió una comisión encabezada por Hilario Valenzuela, Jorge Lebrún, Alberto Castro Salido (líderes estudiantiles), el Dr. Jorge Flores Valdez y José Cruz Bedolla. Hilario reitera las acusaciones contra el gobernador y la solicitud de desaparecer los poderes en el estado. Díaz Ordaz les dijo que no podía intervenir pues no tenía "conocimiento objetivo y a fondo del problema" y que "restablecieran la normalidad en su casa de estudios" y en el estado, y que, después por caminos legales "sometieran sus quejas a una investigación" (El Sonorense, 25/04/1967: 1). Al día siguiente regresó la comisión a Hermosillo, en un ambiente de confusión sobre lo dicho por el Presidente, donde una era la versión del El Imparcial y otra la de El Sonorense. El mensaje para la prensa nacional estaba claro: Novedades: "Restauren la normalidad para atender el problema, dice G.D.O., a los sonorenses"; Ovaciones: "En Sonora exhorta el Presidente a los estudiantes a buscar vías legales” La Prensa, “Apoya la política de Díaz Ordaz. Convenció a estudiantes”.

Después de arduas discusiones la FEUS dio a conocer el acuerdo de que no se realizarían actos de masas, pero continuaría la huelga, incluso pretendieron terminar con el paro en las primarias pero se encontraron con la oposición de los padres de familia. A pesar del esfuerzo de quienes se hicieron eco de la actitud del Presidente el único plantel que levantó la huelga fue el ITSON el 2 de mayo. 
En ese sentido, entre el 26 de abril y el 11 de mayo, no hubo acto de masas, ni paralización en el comercio, pero siguió sin funcionar el sistema educativo. El Imparcial (4/05/1967:1) calculaba que se encontraban "paralizados en el Estado 136 escuelas primarias más de 20 secundarias y 14 planteles de nivel superior”. Además que seguían llegando muestras de apoyo a la FEUS. Mientras esto ocurría se buscaba de nuevo contacto con el presidente, al iniciarse abril una comisión de estudiantes encabezada por Jesús Larios Gaxiola al buscar dicha entrevista fueron recibidos por el secretario particular del Presidente, Joaquín Díaz Cisneros y, el secretario de gobernación, Luis Echeverría, el día 3 de mayo. Otra comisión más amplia que incluía profesores (Manuel Ríos y Ríos y Casimiro Monge), Padres de familia, (Dra. Angelina de Haussman, Concepción G. de Silva, Aurelia Salido e Irma Oloño) y líderes estudiantiles (Rubén Pablos Soto, Jorge Lebrún Almada y Gilberto Oliverio Granillo), salió el día 6 de abril a la Ciudad de México, serían recibido el 12 de mayo.

Se inicia de nuevo la movilización. El 11 de mayo, un día después de que Faustino Félix fuera inscrito ante la autoridad electoral como el candidato del Partido Revolucionario Institucional, se rompió la tregua con un mitin en las escalinatas del Museo, varios oradores tomaron la palabra, José Luis Jardines, secretario de prensa de la FEUS afirmaba, "durante 17 días permanecimos pasivos en acatamiento a la petición del Lic. Gustavo Díaz Ordaz, más al ver como manos ocultas, que obedecen instrucciones del Gobierno Estatal, hacen todo lo posible por mantener la agitación, con intención de retrasar el fallo de las autoridades federales, quizá por temor a que les sea adverso, hemos abandonado nuestra actitud pasiva para seguir buscando unidos pueblo y estudiantes acelerar la decisión que, porque confiamos en el jefe del Ejecutivo de la Nación, será la que todos los sonorenses esperamos” (El Imparcial 12/05/1967: 1 y 4).

Estalla de nuevo la violencia. Sin embargo, la mecha que provocó de nuevo la movilización con fuertes y violentos enfrentamientos ocurrió en la Escuela Vicente Guerrero del barrio El Ranchito, sito en Transversal y Periférico Oriente. A la medianoche del sábado 13 un 
automóvil del municipio tripulado por un policía del Departamento de Investigaciones, Ramón García, junto con un camión del PRI, intentaron detener un carro de la Universidad conducido por estudiantes, el cual ingresó a la escuela y las fuerzas policiacas detrás de él, lo que desató el enfrentamiento. Las campanas repicaron pidiendo apoyo y la gente del barrio bajó en su defensa, de tal modo que obligaron a la policía, que había sumado patrullas, a replegarse. Al día siguiente a las 6:00 horas volvieron a enfrentarse y de nuevo fueron las fuerzas del "orden” rechazadas. Un estudiante salió gravemente herido y 9 personas fueron encarceladas, entre ellas el conocido promotor de box, Oscar "Chapo" Romo.

Con esos antecedentes, el mitin ese día 14 en la tarde fue virulento y terminó a los gritos de “¡a la comandancia de policía!, ¡al Sonorense!, espontáneamente y sin líderes, se formaron dos columnas y salieron airadamente" (E1 Pueblo, 15/05/1967:2). La columna que se dirigía a El Sonorense se desintegró, la otra se dirigió a la comandancia con el propósito de liberar a los presos, al llegar fueron recibidos a balazos desde la azotea, por lo que se entabló una batalla, según la policía en el zafarrancho hubo un saldo de trece heridos y seis arrestados más (El Imparcial, 15/05/1967: 1 y 8). Ese mismo diario llamaba en la Editorial ¡Violencia No! y pedía "Que intervenga la fuerza federal con sus recursos pacifistas para que no se derrame más sangre de hermanos". El lunes 15, según un boletín de la FEUS, fueron asaltadas por la policía las primarias Vicente Guerrero, Ángel Arreola, Ignacio Fimbres, Vicente Mora y la Escuela Prevocacional, siete automóviles fueron incendiados, fueron atacados los despachos de los abogados Rogelio Rendón y Fox Romero, el Supermercado Insurgentes de la Colonia Olivares, El Sonorense fue balaceado. La Ferretería Abascal, la Casa Oloño y los Almacenes Vallejo, fueron asaltados para apoderarse de armas y parque (El Imparcial 16/05/1967: 1 y 7). La violencia se había desatado mediante la provocación y la oposición había caído en ella. En esos días las aprehensiones y los amparos estaban a la orden del día. 
Para el día 16 la FEUS llamó a un paro en los comercios mientras se esparcían rumores de la inminente intervención del ejército. Y, el día 17, se tenían programados parar en la mina de Cananea y se realizaban pláticas con igual sentido con los ferrocarrileros de Empalme y los estibadores de Guaymas. En ese día igual que el anterior se llevaron a cabo una serie de hechos violentos.

El ejército toma el control. El día 17 de mayo el estado de Sonora y la capital, Hermosillo, se encontraban bajo el control del ejército. En la Ciudad de México, la Secretaría de Gobernación informaba que un día antes se había recibido el oficio 1544 del H. Congreso del Estado, firmado por los diputados Antonio Medina Hoyos y Guillermo N. Cajigas donde se solicitaba la intervención del ejército para restablecer el orden (Novedades, 17/05/1967: 5). El Gral. Luis Alamillo Flores, Jefe de la IV Zona Militar declaraba, "por órdenes de la Presidencia de la República..., desde las primeras horas de hoy, fuerzas armadas del ejército venidas por tierra, aire y más de distintas partes del país, están vigilando la conservación del orden y la tranquilidad social en este lugar" (E1 Día, 17/05/1967: 5, archivo CIDOC) y, para que quedara claro afirmaba, "la autoridad constitucional del Estado sigue siendo el gobernador Luis Encinas, y, el ejército y la marina "van a estar subordinados a su autoridad" (El Sol de México, 18/05/1967: 5, CIDOC).

Al anochecer, a las 19:00 horas, el primer batallón de fusileros paracaidistas al mando del General José Hernández Toledo, después de desfilar por las calles de Hermosillo, rodean la universidad, especialmente por el frente, donde se pone una bazuca en la puerta de la entrada, El Gral. Hernández Toledo, “armado con fusil ametralladora, se internó en el edificio universitario" y exigió a los estudiantes salieran pues tenía orden de ocuparla. Los estudiantes comenzaron a salir llorando, cantando el Himno Nacional y Universitario, siendo recibidos fuera del campus por padres de familia, y pueblo en general con quienes marcharon a Palacio de Gobierno. Ahí se realiza un mitin y el estudiante de Derecho, José Alberto Castro Salido, pidió orden, dignidad y dispersión (Revista Gente \#35, 17/06/1967: 31). A partir de entonces 
el ejército se desplegó por toda la geografía sonorense desalojando a los paristas, ocupando escuelas. En el caso de la universidad la ocupación se realizó hasta el 26 de mayo recibiendo entonces las instalaciones el rector Moisés Canale que, a decir de "El Sonorense 26/05/1967:1), se había comprometido a que "se normalizarían las labores académicas". En buena medida la salida del ejército del campus se debió a la actitud de los maestros que se negaron a laborar mientras los militares la ocuparan, lo que había motivado a Carlos Moncada (El Sonorense, 25/05) a expresar, "el Consejo Universitario debe intervenir con los maestros que se niegan a volver por el ejército". Si bien en otras instituciones poco a poco la actividad académica se normalizó, en la Universidad no ocurrió así. Desde el 19 del mismo mes, con la universidad ocupada por el ejército, la Junta de Directores y el Rector acordaron suspender las clases y reanudarlas en septiembre (El Sonorense, 20/05/1967: 1 y 6). El 30, con el ejército fuera del campus, vuelven a ratificar el acuerdo de volver a clases hasta el 2 de septiembre, o sea, con Luis Encinas fuera de la gubernatura. Eso es, seguramente, lo que no le perdonaron a Canale. Además de la Universidad no volvieron a clases hasta tiempo después la Normal del Estado y la Escuela de Artes y oficios. El 19 de mayo el frente Magisterial AntiImposicionista en una reunión en el Museo y Biblioteca acordó poner fin a la huelga.

Las elecciones de aquel año. Entre cierre de actividades en la Universidad y los líderes estudiantiles exiliados en Tucson, líderes sindicales defenestrados, encarcelamiento de participantes, funcionarios que dejan de serlo, una campaña del candidato oficial que prosigue encontrando molestar e inconformidad, con un Partido Acción Nacional que aprovecha la coyuntura y nombra a un fundador de la Universidad, el Lic. Gilberto Suárez Arvizu, su candidato a gobernador, se llevan a cabo las elecciones el domingo 2 de julio. Siendo declarado vencedor por abrumadora mayoría, Faustino Félix Serna, lo cual no es creíble, muy probablemente el PAN triunfó por primera vez, sin embargo, solo le reconocen 
el triunfo en Hermosillo, siendo la primera capital del Estado conquistada por la oposición, y 4 municipios menores más.

El día $1^{\text {o }}$ de septiembre los líderes vuelven del exilio siendo recibidos apoteóticamente. Al día siguiente la plenaria de la FEUS da por terminado el movimiento de huelga.

Un día después, el rector, Moisés Canale, es secuestrado, ultrajado, retratado y obligado a renunciar a pesar de la oposición del Consejo Universitario, quienes realizaron incluso una manifestación el 5 de septiembre para apoyarlo. Finalmente, la renuncia con carácter irrevocable se ejecuta. Canale dijo, entre otras cosas "tras el ponderado análisis del problema político social acaecido recientemente entre nosotros, de su repercusión universitaria, de las causas que lo iniciaron y de los que lo fueron complicando, de las incidencias que convergieron en su desenvolvimiento ulterior y de los efectos del mismo que hemos visto producirse en diversos sectores de nuestra comunidad, he llegado a la conclusión de que mi presencia en las oficinas de esta Rectoría, no será en lo sucesivo un factor que continúe impulsando el progreso en la Universidad de Sonora, es por ello que decido retirarme (El Imparcial, 5/09/1967: 1 y 6). Años después a Aldaco le dijo: “cuando ocurrió el lío de la universidad, se me dijo: expulsa a los muchachos. Pensé: ‘qué saco yo con eso'; expulsar muchachos en ese momento hubiera sido romper con ellos y entonces se hubiera dado al traste con la única conexión que existía con esos grupos" $(2002,65)$. En su carta de renuncia al Consejo Universitario, entre otras cosas, afirma: “era imposible, por otro lado, resolver un conflicto no universitario de la magnitud y características eminentemente políticas que mostraba, en aquellos días el problema, con los medios puramente universitarios que la ley interior pone a disposición de sus autoridades. Llegar a la suspensión o expulsión de jóvenes de lo que tanto hablaron muchos y mucho desearon otros, en nada hubiera ayudado, es fácil entender por qué” (El Imparcial, 5 de septiembre de 1967, pp. 1-6, sección I). 
A pesar que el presidente de la República había expresado al Consejo Universitario, "quizá nadie como yo, tenga más interés en que se aclaren completamente los hechos y que los responsables reciban el castigo que la ley señala” (El Imparcial, 8/08/1967: 1), los responsables nunca fueron conocidos ni castigados.

Causas. Entendemos por causas, los grandes problemas que están subyaciendo y que hacen posible la movilización, muchas veces sin que los protagonistas tengan cabal conciencia del mismo.

En primer lugar, el agotamiento del sistema político mexicano de partido único con elecciones fraudulentas e imposiciones de carro completo, eso que Vargas Llosa caracterizó como la dictadura perfecta (El País, 1/09/1990). Que chocó con una corriente cívico liberal presente en el estado de Sonora desde el siglo XIX (Almada, 1991).

En segundo lugar, un contexto político internacional de intensa movilización política e incluso militar. La guerra de Vietnam es, sin duda, el proceso más significativo al respecto, sintomáticamente, el 8 de mayo de 1967, la Revista Life en Español dio a conocer el conflicto sonorense a nivel mundial, "un raro caso de violencia en la política mexicana" y, en la portada, una fotografía de vietnamitas en refugios antiaéreos en Saigón y el título del reportaje central, "Vietnam bajo el fuego". La guerra de Vietnam, por otra parte, generó un movimiento pacifista sobre todo al interior de Estados Unidos de Norteamérica, el movimiento hippie, que se combinaba y fortalecía con la movilización paralela a favor de los derechos civiles de los afroamericanos, en una orientación pacifista liderada por Martin Luther King y otra violenta del grupo de los Panteras Negras (Davis et al, 1972). En América latina después de la Revolución Cubana comenzaron a desarrollarse organizaciones y movimientos guerrilleros en varios países de América Latina, las Fuerzas Armadas Revolucionarias de Colombia (FARC), el Ejército de Liberación Nacional (ELN); los Tupamaros en Uruguay; la izquierda del peronismo (los Montoneros) en Argentina; el MIR 
en Chile, en México a la tradicional guerrilla rural de Genaro Vázquez y Lucio Cabañas, se sumarían otras expresiones ahora urbanas nutridas por los movimientos estudiantiles, la más destacada, la Liga Comunista 23 de Septiembre.

En los años sesenta y principio de los setenta el país y el mundo son testigos de una fuerte movilización estudiantil que tuvo su cenit en 1968, cuando hubo manifestaciones en París, Francia, Alemania, algunas universidades estadounidense especialmente Berkeley, Argentina, México, y otros países (Cohn-Bendit 1987; Bensaïd, Daniel y Henri, Weber 1968; Revueltas 1978; Wing Shum et al 1971).

En México: en 1960, un movimiento estudiantil en Guerrero terminó en una masacre y la caída del gobernador; en 1961 una manifestación en la Ciudad de México en apoyo a la Revolución Cubana fue reprimidas por los granaderos; en 1962 los estudiantes de la Universidad Autónoma de Puebla inician un movimiento por reforma universitaria; al año siguiente, en la Universidad Michoacana de San Nicolás de Hidalgo se desarrolló un conflicto que desembocó en la renuncia del rector progresista, Eli de Gortari; en 1964, los estudiantes poblanos con apoyo popular derrocan al gobernador Nava Castillo; en junio de 1965, en México D.F., es reprimida una manifestación de apoyo al pueblo de Vietnam; en agosto de ese año estalló el movimiento médico y todas las escuelas de medicina se fueron a la huelga por solidaridad; pararon también la Facultad de Ciencias, la Nacional de Economía y Ciencias Políticas de la UNAM; en 1966, los estudiantes de la Universidad Autónoma de Sinaloa conquistan la autonomía; en Durango libran una lucha para que sea procesado en el estado el mineral del Cerro del Mercado que se llevaba a la siderúrgica de Monterrey; en Michoacán el asesinato de un estudiante casi le cuesta la silla al gobernador, movimiento aplacado con la entrada del ejército y, el movimiento en la UNAM que obligó a la renuncia del Dr. Ignacio Chávez a la rectoría en 1967; el movimiento estudiantil y popular en Sonora; la huelga de los estudiantes de la Escuela de Agricultura "Hermanos Escobar" de Ciudad Juárez, Chih., que buscaban pasar de privada a pública y que levantó importantes muestras 
de solidaridad; el '68 mexicano; las luchas por la democratización universitaria en la Universidad de Nuevo León en 1971 y la Universidad de Autónoma de Sinaloa en 1972; Oaxaca, Guerrero (Guevara 1983, 145-150). O sea, una oleada de movilizaciones estudiantiles que tuvo su cenit en 1968 y que llegaron a su fin en su parte medular hacia 1974, aunque siguiera habiendo expresiones.

Hay dos procesos más que ayudan a explicar no sólo al movimiento del '67 en Sonora, por una parte, el inicio de la crisis del modelo de desarrollo de la posguerra a nivel mundial; del modelo sustitutivo de importaciones en México (Navarrete 1973; Urquidi 1973; Blanco 1981) y, del modelo de los valles agrícolas en Sonora. De manera general, del tránsito de una etapa de crecimiento sostenido y elevación de niveles de vida a otra con crecimiento más lento e inestable con aparición de problemas estructurales.

Por otra, el inicio de la masificación de la educación superior (Meyer y Schofer 2006: 20; Hobsbawn, 2007: 298; Fischman, 2008: 244), la llegada de los nacidos en la posguerra, el fenómeno llamado en USA "baby boom", que va a transformar a la universidad en lo que los expertos definen como de tradicional a moderna: la tradicional era pequeña y elitista, sólo los hijos de familias de altos ingresos tenían acceso. La moderna, en cambio, es de masas, con los sectores medios como los mayoritarios, incluso con estudiantes venidos del estrato de trabajadores asalariados; en ese sentido, hay un cambio en la composición social de los estudiantes. En la tradicional, las opciones curriculares más importantes eran las de corte liberal, derecho, medicina, ingeniería; la moderna diversifica las opciones curriculares y de instituciones. El papel asignado a la primera consiste en la reproducción de las élites, los egresados laboran como funcionarios del Estado, en las empresas, con cargos directivos o como profesionistas independientes; en la moderna se suman los egresados que laboran como trabajadores asalariados, incluso en actividades productivas (Casillas 1987; Fuentes 1988). 
Ambos procesos, el agotamiento de los modelos de desarrollo y la masificación de la educación se encuentran contrapuestos, es decir, comienzan a llegar masivamente a la educación superior cuando comienza a evidenciarse signos de crisis de los modelos de desarrollo hasta entonces exitosos.

Consecuencias. La primera es, sin duda, que obligó al régimen a abrirse, a democratizarse; que se materializó en la "apertura democrática" de Luis Echeverría y en la reforma política de José López Portillo, en esta transición inconclusa y hasta hoy fallida hacia la democracia.

En el caso de la Universidad de Sonora, como en otras, el movimiento rompió la perfecta concordancia entre el interés de los sectores universitarios y el gobierno estatal (representante del Estado Nacional) y los empresarios locales. Las relaciones entre ellos pasan de tersas a conflictivas, los estudiantes se radicalizan, incluso algunos se suman a la lucha armada y los trabajadores universitarios con el tiempo se sindicalizan. En lo inmediato la Unison transita de una etapa de tranquilidad social a otra de mucha movilización y enfrentamiento. 


\section{Referencias}

Aldaco, G. B. “Universidad de Sonora (Nuestros Rectores)”. Hermosillo, Sonora, México: Universidad de Sonora. 2002

Almada, Bay I. "La conexión Yocupicio: soberanía estatal y tradición cívico liberal en Sonora, 1913-1939. México D.F: El Colegio de México, 2009.

Almada, F. Diccionario de Historia, Geografía y Biografía Sonorenses. Hermosillo, Sonora, México: Gobierno del Estado de Sonora, Instituto Sonorense de Cultura, tercera edición 1990.

Arredondo, López, D. "La tutoría a estudiantes de economía en la Universidad de Sonora", Edición electrónica gratuita. 2008 Texto completo en www.eumed.net/tesis/ 2008/jdal/

Ayala, Encinas, C. "El fin de una ilusión" (ensayo político-cultural sobre los años setentas en la Universidad de Sonora). Hermosillo, Sonora, México: Consejo Nacional para la Cultura y las Artes (CNCA). 2000.

Barbero, M. I., García Molina, F. R. Rubén L, Berenblum, Jorge y Saborido, R.E., “Historia Económica y Social General”. Córdova, Argentina: Ediciones Macchi. 1998.

Bensaïd, D. y H. Weber, 1968. Mayo 68: un ensayo general. México: Ediciones ERA, primera edición en español, 1969.

Burgos, B., A. Mungaray y J., Oceguera, "Estructura económica y demanda de educación superior en el noroeste de México”. México: ANUIES. 2003.

Carmona, F., et al, "El milagro mexicano”. México: Editorial Nuestro Tiempo. 1973.

Castellanos, Moreno, M. "Historia de la Universidad de Sonora” (1938-1953). Hermosillo, Sonora, México: Editores, Arnulfo Castellanos Moreno, Gabriela Rosales Gutiérrez y la Secretaria de Prensa del STAUS. Hermosillo Sonora, Una segunda edición por Editorial de la Universidad de Sonora, Hermosillo, Sonora, México, 1991.

Castellanos, Moreno, M. "Historia de la Universidad de Sonora" (1953 -1967). Editores, Arnulfo Castellanos Moreno y Gabriela Rosales Moreno. Hermosillo, Sonora. 1993.

Castellanos, Moreno, M. "Historia de la Universidad de Sonora" (El STAUS y el desarrollo académico)” Tomo IV. Guadalajara, Jalisco: Edición personal. 2006.

Castellanos, Moreno, M. "Historia de la Universidad de Sonora” (en una época de crisis) Tomo III. Guadalajara, Jalisco: Edición personal. 2007.

Castrejón, Diez, J. y M. Pérez Lizaur. “Historia de las Universidades Estatales”. México: SEP, Edición Selecciones Tipográficas. 1976.

Cohn-BendiT. "La revolución y nosotros que la quisimos tanto". España: Editorial Anagrama. 1987.

Cueva A. "El desarrollo del capitalismo en América Latina. México”: Siglo XXI Editores, décima edición en español 1986. 1977. 
Davis Y. Á. et al. "Si llegan por ti en la mañana... Vendrán por nosotros en las noche”. México Siglo XXI editores. 1971.

De Santiago, J. "Lodos de aquellos polvos". Guadalajara, Jalisco, México: Santa Paula Editorial. 2011

Duarte, Rodríguez R. "Días de fuego (El movimiento universitario sonorense de los años 70”. Hermosillo, Sonora, México: Universidad de Sonora y Germinal. , 2003.

Durand, Villalobos J. "Poder, gobernabilidad y cambio institucional en la Universidad de Sonora (1991-2001). México D.F: ANUIES. 2006.

Estévez N. y H. Etty. Panorámica de la investigación Educativa en la Unison (Primer Inventario de Proyectos). Hermosillo, Sonora, México: Editorial UNISONO. 1989.

Encinas, Johnson L. Progreso y Problemas de México. México, Editorial Stylo. 1954.

Encinas, Johnson L. "La alternativa de México (conflictos, causas, caminos)". México D.F.: Ediciones Sonot. 1969

Esquivel, Casas, A. "Posición Pedagógica Social y Filosófica de la Universidad. Hermosillo, Sonora, México: Edit. Universidad de Sonora. 1942.

Flores Urbina, Alberto. La Educación Superior en el Estado de Sonora. Hermosillo, Sonora, México: Edición UNISON.

Galaz A. F. "Dejaron Huella en el Hermosillo de ayer y de Hoy". Hermosillo, Sonora, México: Gobierno del Estado de Sonora, segunda edición, 1996.

García, L. Siete notas para las Bellas Artes. Hermosillo, Sonora, México: Editorial UniSon. 1992.

García, L., A. Hernández, E. López, R. Díaz, G. Barraza y F. Cota Madero, asesoría en fotografía de Guillermo Moreno, Memoria gráfica de la Universidad de Sonora. , Hermosillo, Sonora, México: Universidad de Sonora. 1992.

García L. "Memoria gráfica del deporte universitario". Hermosillo, Sonora: Universidad de Sonora, Colección Memoria gráfica \#1, asesor fotográfico, Guillermo "memo" Moreno. 1996.

García L. "Memoria gráfica del teatro universitario (1954-2004). Hermosillo, Sonora, México: Universidad de Sonora. , 2006.

González, Avelar M. y Lara Sáenz, L.” Legislación Mexicana de la Enseñanza Superior”. México: Universidad Nacional Autónoma de México. 1969.

Guevara, Niebla G. "El saber y el poder. México”: Universidad Autónoma de Sinaloa., 1983.

Hobsbawn Eric,. The age of the extreme: a history of the world, 1914-1991. Inglaterra: Michael Joseph and Pelham Books. 1994

Hobsbawn E. 2007. "Historia del siglo $X X$ ”. Buenos Aires: Crítica, Grupo Editorial Planeta (2010).

Kobayashi J., J. Zoraida Vázquez, D. Tanck de Estrada, A. Staples y E. Trabulse. "Historia de la educación en México”. México: SEP. 1976. 
Lagarda, Lagarda, I. "El color de las Amapas: crónica de la guerrilla en la sierra de Sonora”. Hermosillo, Sonora, México, Liceo Tecnológico de Sonora A.C., Instituto Tecnológico Superior de Cajeme, Universidad tecnológica del Sur de Sonora. 2007.

Levy C., D. "Educación superior y el Estado en Latinoamérica”. Desafíos privados a predomino público. México, Colección problemas educativos de México. FLACSO_UNAM, edición en español. 1991.

Macías, Enríquez A. "Historia de la facultad de derecho de la Universidad de Sonora". Editorial Garabatos SA de CV. Hermosillo, Sonora, (segunda edición). 2006

Maddison, A. "Las fases del desarrollo capitalista”. Una historia económica cuantitativa. México: El Colegio de México, Fondo de Cultura Económica; 1986. 1982.

Maddison A. “La economía mundial: 1820-1992”. Análisis y estadísticas. Francia: OCDE. 1995

Inzunza M. y Terán, L. "El movimiento universitario en Sonora y Sinaloa”. Culiacán, Sinaloa, México: Universidad Autónoma de Sinaloa. 1979.

Mendivil, Rincón, J. ’La Universidad de Sonora: Desde_su fundación”. Hermosillo, Sonora: Publicidad Mendivil. 1975.

Mercado, Andrews, I. "El Día que Exploto la rabia (Huelga 1967 en Sonora)”. s.e. Folleto de Hermosillo Sonora. 1973.

Moncada, Ochoa, C. "Diez en el poder”. México: Edamex. 1997.

Moncada, Ochoa C. "Historia General de la Universidad de Sonora”, Tomo I, El principio del principio 1938-1953. Hermosillo, Sonora, México: Editorial Uni-Son. 2005.

Moncada, Ochoa C. "Historia General de la Universidad de Sonora”, Tomo II, legislación universitaria 1938-1991. De la autonomía formal a la autonomía real. Hermosillo, Sonora, México, Editorial Uni-Son. 2006.

Moncada, Ochoa, C. "Historia General de la Universidad de Sonora", Tomo III, crecimiento, política y crisis 1953-1973. Hermosillo, Sonora, México: Editorial UniSon. 2007.

Moncada, Ochoa, C. "Historia General de la Universidad de Sonora", Tomo IV, la encrucijada 1973-1992. Hermosillo, Sonora, México: Editorial Uni-Son. 2009.

Moncada, Ochoa, C. "Historia General de la Universidad de Sonora”, Tomo V, hacia la excelencia 1992-2009. Hermosillo, Sonora, México: Editorial Uni-Son. 2009.

Montoya, Lara, J. "Universidad Espacio y Arquitectura (Memoria Gráfica de la Arquitectura de la Universidad de Sonora)". Hermosillo, Sonora, México: Universidad de Sonora. 1996.

Moreno, Soto, A., F. Ochoa, Valenzuela Miranda, M. Darío y Á. Bracamontes, "Los Aguiluchos (Movimiento Popular Estudiantil de 1967 en Sonora)". Hermosillo, Sonora, México: Universidad de Sonora. 1985.

Moreno, Soto, A. "Historia del desarrollo de la Universidad de Sonora". Hermosillo, Sonora, México: edit. UNISONO, Colección No. 12. 1991. 
North, Douglas C.," Instituciones, cambio institucional y desempeño económico”. México: FCE. 1993.

Portantiero, J. "Estudiantes y política en América latina" (1918-193): el proceso de la reforma universitaria. México: Siglo XX Editores. 1978.

Quiroz, Martínez., 1949. "Monografía Histórica de la Universidad de Sonora". Hermosillo, Sonora, México. Ponencia presentada en la "Novena sesión plenaria del Congreso Mexicano de Historia". Hermosillo, Sonora. Diciembre 1949 (versión mecanográfica). Hermosillo, Sonora, México: Universidad de Sonora, primera edición 1999.

Revueltas, J. 1978. “México 68: juventud y revolución”. México: Ediciones ERA, segunda edición 1969.

Rivas, Ontiveros, J. “La izquierda estudiantil en la UNAM: organizaciones, movilizaciones y liderazgos” (1958-1972). México: UNAM y Miguel Ángel Porrúa. 2007.

Rivera, Rodríguez, G. "Breve Historia de la Educación en Sonora. (Historia_de la Escuela Normal del Estado)". s.e. Hermosillo Sonora.

Silva, Herzog J. "Una historia de la universidad de México y sus problemas”. México: Siglo XXI Editores S.A., tercera edición 1979. 1974.

Sortillon, Valenzuela M. "Memorias de la Universidad de Sonora y de su escuela de Ingeniería”. Hermosillo, Sonora, México: Universidad de Sonora. 1998.

Steger, H. "Las Universidades en el cambio social en América Latina. México: Fondo de Cultura Económica", Primera edición en español, 1974. 1967.

Ramírez, J. "Historia contemporánea de Sonora (1929-1984)”, Hermosillo, Sonora, México: quinto tomo de la historia general de Sonora. Gobierno del Estado de Sonora. 1985.

Ramos, Salas, J. (compilador), "Investigaciones Educativas en Sonora”. Hermosillo, Sonora: Editorial UNISONO. 1999.

Uribe, García J. “Universidad de Sonora”. El Museo, Hermosillo, Sonora México: editorial UniSon. 2001.

Van deer Wee H. "Historia Económica Mundial del siglo XX: prosperidad y crisis". Reconstrucción, crecimiento y cambio, 1945-1980. Munich, Alemania. Barcelona, España: Editorial Crítica, SA. 1984.

Vasconcelos, J. “El desastre”. México: Editorial Trillas (primera edición). 1998.

Vázquez, Ruiz, M. (coordinador) y otros, "Economía sonorense más allá de los valles". Hermosillo, Sonora, México: Universidad de Sonora. 1991.

Velarde Romero J. s/f. “El movimiento magisterial en Sonora (El ardiente verano de 1967)”. Hermosillo, Sonora, México: Ediciones la Voz.

Verdugo, Córdova J. "El movimiento estudiantil en la Universidad de Sonora de 1970 a 1974" (un enfoque socio histórico a partir del testimonio oral). El Colegio de Sonora, Hermosillo, Sonora, México. 2004 
Vidal, A. "Los nuestros (a propósito de centenarios)". Hermosillo, Sonora, México, editora la voz de Sonora S.A. de C.V. 1999.

Wing, Shum, J., D. Rodríguez Chaurnet, J. Carreón, F. Burgueño, E. Leiva, P. Gómez, A. Bonilla, M. Aguilar, I. Hernández y C. Schaffer. "Los estudiantes, la educación y la política”. México: Editorial Nuestro Tiempo. 1971.

Wood, Gordcon S. "La revolución norteamericana". USA: Weidenfeld \& Nicolson. Barcelona, España: Grupo Editorial Random House Mondadori, S.L., primera edición en español, 2003. 2002.

\section{Capítulo de libro}

Arredondo, López, J. Economía y educación. "El tiempo de la industrialización dependiente y el nuevo espacio universitario”. En Darío Arredondo (coordinador), Tiempo y Espacio. Hermosillo, Sonora, México: Editorial Universidad de Sonora, 107-113. 2007.

Ayala, J. “La crisis económica evaluación y perspectiva”. En González Casanova Pablo y Enrique Florescano (coordinadores), México hoy. México: Siglo XXI Editores: 1994. 1979.

Basave, Fernández del Valle, A. "La universidad en la historia. En, ser y quehacer de la universidad". Estructura y misión de la universidad vocacional. San José de Costa Rica: Ediciones Promesa S.A., segunda edición. 1983.

De la Peña, G. “Educación y cultura en el México del siglo XX”. En un siglo de educación en México, Pablo Latapí S., coordinador, tomo I. México DF: Fondo de Cultura Económica, Consejo Nacional para la Cultura y las Artes, Fondo de Estudios e Investigaciones Ricardo J. Zevada. (1998).

García, Guadilla, C. "Los profesores universitarios y su historia”. En (prologo) Parra Sandoval María Cristina, "las intimidades de la academia. Un estudio cuanticualitativo sobre la dinámica de la profesión académica". Mérida, Venezuela, Universidad de Zulia. Colección textos universitarios. (2008).

González, González E. “La universidad Virreinal, una corporación”. En Marsiske, Renate (coordinador), La universidad de México. Un recorrido histórico de la época colonial al presente. México. CESU-UNAM: 2001.

Hall, P., A. y R. C.R. Taylor "Political Science and the Three NewInstitutionalisms", en Soltan Ann Arbor. et al., Institutions and Social Order. USA: The University Of Michigan Press. 1998.

Rollin, K. y R. Ramírez, “La educación superior en el umbral del siglo XXI”. En, un siglo de educación en México, Pablo Latapí S. coordinador, tomo II. México DF: Fondo de Cultura Económica, Consejo Nacional para la Cultura y las Artes, Fondo de Estudios e Investigaciones Ricardo J. Zevada. 1998.

Lapati, Sarre, P. “Un siglo de educación nacional: una sistematización”. En Pablo Latapi (coordinador), un siglo de educación en México. Tomo I. México DF: Fondo de 
Cultura Económica, Consejo Nacional para la Cultura y las Artes, Fondo de Estudios e Investigaciones Ricardo J. Zevada. 1998.

Navarrete M. “Distribución del ingreso en México: tendencia y proyección a 1980”. Selección de Leopoldo Solís, la economía mexicana. I. análisis por sector y distribución. México: Fondo de Cultura Económica. 1973.

Tedesco, J. y H. Blumental. "Desafíos y problemas de la educación superior en América Latina”. En Galán María Isabel y Dora Elena Marín (coord.). Investigación para evaluar el curriculum universitario. México; UNAM/Porrúa.

Tünnermann Bernheim, C. "Breve historia del desarrollo de la universidad en América Latina”. En "educación superior en el umbral del siglo XXI. Caracas, Venezuela: UNESCO-Editorial CRESALC, PP. 11-38. 1996.

Urquidi, L. V. "La distribución del ingreso y el desarrollo económico". Selección de Leopoldo Solís, la economía mexicana. I. análisis por sector y distribución. México: Fondo de Cultura Económica. 1973.

\section{Artículos de revista}

Blanco, J. "El desarrollo de la crisis en México, 1970-1976”. El trimestre económico. En Rolando Cordera, desarrollo y crisis de la economía mexicana. México: FCE. 1981.

Blanco, J. "Génesis y desarrollo de la crisis en México, 1962-1979”. Investigación Económica \# 150 octubre-diciembre: 25-88. 1979.

Burton C. R. "Diversificación de la educación superior: viabilidad y cambio". Universidad futura, vol. 5 \# 14, Universidad Autónoma Metropolitana-Azcapotzalco. México. 1994.

Carbajosa, Martínez, D. "El análisis institucional como teoría crítica de las formas sociales”. Revista Mexicana de Sociología \# 1, enero-marzo de 1984, pp. 263-271.

Casillas, M. "Notas sobre el proceso de transición de la universidad tradicional a la moderna. Los casos de la expansión institucional y la masificación”. Sociológica Núm. 5, UAM, Azcapozalco, otoño de 1987, México, pp. 121-144.

Castellanos, Moreno M. "Nacimiento del Departamento de Ciencias Sociales". Revista Versiones, Hermosillo, pp. 11-13. 1992.

Cota, Madero, F. "sobre el valor poético de un ser tan esplendido con Ahumada". Páginas del desierto No. 10, octubre de 1998, Hermosillo, Sonora.

Dubet, F. "Conflicto de normas y ocaso de la institución”. Estudios sociológicos. México: vol. XXII, núm., 64, pp. 3-24. enero-abril 2004

Farfán, Mendoza, G. "El nuevo institucionalismo histórico y las políticas sociales". Polis: investigación y análisis sociopolítico y psicosocial, primer semestre, año/vol. 3, número 001. Universidad Autónoma Metropolitana- Iztapalapa. Distrito federal, México, pp. 87-124. Tomado de http://redalyc.uaemex.mx/src/inicio/ artPdfRed.jsp?¡Cve=72630115. 2007. 
Fischman, G., E. "Las universidades Públicas en el siglo XXI. Grandes expectativas, algunas promesas y muchas incertidumbres". Universitas Humanística \# 66, julio-diciembre del 2008, pp. 239-270. Bogotá, Colombia. Documento pdf

Fuentes, Molinar, O. abril-junio de "Las épocas de la Universidad Mexicana". Cuadernos Políticos \# 36, pp. 47-55. 1988.

Germán-Soto, V. "Generación del producto interno bruto mexicano por entidad federativa, 1940-1992". México: El Trimestre Económico, vol. 72(3): 617-653. (2005)

Maldonado, A. "Los organismos internacionales y la educación en México. El caso de la educación superior y el Banco Mundial”. Perfiles Educativos \#87, enero-marzo 2000. México DF, Universidad Nacional Autónoma de México. 2000. http://redalyc.uaemex.mx/pdf/132/13208704.pdf.

Mejía, Lugo, E. "Los cambios, las instituciones y el proceso de crecimiento económico en el enfoque institucionalista”. México: tiempo Económico, \# 21, vol. VII, segundo cuatrimestre. 2012.

Meyer, J. y W. E. Schofer, “La Universidad en Europa y en el mundo”. Revista Española de Educación Comparada \#12, 15-36. 2006.

Molina, Freaner, G., Carrión Contreras, E., Larios Velarde, R., L. Enríquez, C. y Hernández López, S., "Modelo de Departamentalización de la Universidad de Sonora". México DF: Comité de Educación Pública \#3, ANUIES, pp.109-124. Diciembre de 1985.

Moncada, Ochoa, C. "Vida política de Herminio Ahumada". Lecturas de la lechuza, Hermosillo, Sonora. Viernes 30 de enero de 1998.

Moreno, Moreno, P. “Crisis y modernización de la educación superior en México”. Revista del Colegio de Sonora, año I, No. 1, pp. 105-116. 1989.

Moreno, Soto, A. "Herminio Ahumada Ortiz y la fundación de la Universidad de Sonora”. Revista Universidad de Sonora, nueva época \#12, Hermosillo, Sonora, Universidad de Sonora, diciembre de 1998. Pp. 44-46. 1998.

Moreno, Soto, A. abril de 1988. "Universidad de Sonora: cuarenta y cinco aniversarios de vida\#. Revista de la Universidad de Sonora \# 6, pp. 10-22. Reproducido bajo el título, larga transición de la universidad. Hermosillo Sonora, México: UniSono \# 65, 31 de octubre 1 de 1990.

Navarro, López, C. "La situación política Estatal, La Universidad de Sonora y la ley 4". Revista Versiones. Revista del colectivo de análisis de Sociología y Administración Pública. STAUS. Hermosillo, abril de 1992, pp. 14-16.

Pérez, Pérez, G. y L. Valencia E. 2004. El neoinstitucionalismo como unidad de análisis multidisciplinario. Mérida, Venezuela: Actualidad Contable faces, enero-junio, año/vol. número 008. Universidad de los Andes, pp. 85-95. 1992.

Ramírez, J. "Hipótesis acerca de la historia económica y demográfica de Sonora en el periodo contemporáneo (1930-1983)". Hermosillo, Sonora, México: Cuadernos del viejo Pitic. Colegio de Sonora, 1985. 
Rico, M. "Higinio Blatt, Sociedades de la academia de política de la Universidad de Sonora", Revista de la Universidad de Sonora, Nueva época \#2, noviembre de 1994. Pp. 3940.

Rodríguez, R. "Cronología de la reforma a la ley orgánica de la Universidad de Sonora”. Foro Universitario 95, diciembre de 1991.

Rodríguez, R. "Origen y desarrollo de la educación superior en Sonora”. Estudios Sociales, vol. VIII, núm. 13, enero-junio de 1997. Hermosillo, Sonora, México; CIAD, ColSon, UniSon. (1997).

Schara julio Cesar, "La Universidad Clásica Medieval, origen de la Universidad latinoamericana”. México, Universidad Autónoma Metropolitana-Xochimilco: Reencuentro (análisis de problemas universitarios), \# 045. 2006.

Scherz, García L. "La universidad del siglo XX”. Entre Napoleón y Humboldt. Caracas, Venezuela: Revista Nueva Sociedad \# 84, julio-agosto, pp. 91-99. 1986.

Sierra L., J. e I. Bustillos. "Fundación de la Universidad de Sonora y de la ECA". Hermosillo, Sonora, México: Centro de Estudios de Desarrollo Gerencial, ECA, Universidad de Sonora, Agosto de 1994, número 3, año 1. 1994.

Suárez, Arvizu, G. "Universidad de Sonora: antecedentes históricos". Revista de la Universidad de Sonora \#2, Hermosillo, abril de 1983, pp. 31-36. 1983.

Vidal, A. "vida y obra de Herminio Ahumada Ortiz". 1900-1983. Lecturas de la lechuza, viernes 30 de enero de 1998. Hermosillo, Sonora.

Vidal, A.” La sombra de Herminio Ahumada: fiel a la luz y a sí mismo". Páginas del desierto No. 10, octubre de 1998, Hermosillo, Sonora.

Tesis

Rangel, Hernández L. “La Liga Comunista 23 de Septiembre 1973-1981”. Historia de la organización y sus militantes. Tesis de Doctorado en Historia, Universidad Michoacana de San Nicolás de Hidalgo. Morelia, Michoacán, México. 2011.

Rosales, Gutiérrez, G. "Historia de la Universidad de Sonora (Reforma Universitaria 19671973.)”_s.e .Tesis Profesional Licenciado en Historia, Universidad de Sonora. Hermosillo, Sonora, julio de 1996.

Ruiz, Zhenia, S. y Vela Cid L. "Cronología Histórica de la Prensa Oficial de la Universidad de Sonora, Unidad Regional Centro 1947-1997. Tesis de Licenciado en Ciencias de la Comunicación de la Unison. Hermosillo, Sonora, junio de 1999.

\section{Ponencias}

Cortez, Román, N. “Del desierto al Zócalo...Crónica del movimiento estudiantil de la Universidad de Sonora, 1991-1992”. Hermosillo, Sonora: Memoria del XXII Simposio de Historia y Antropología de Sonora. 1997

Díaz, Castañeda, R. "Esbozo histórico de la Universidad de Sonora”. Hermosillo, Sonora, México: Memoria XII Simposio de Historia y Antropología. (1987).

Encinas, Blanco, Á. "Vida deportiva del Lic. Herminio Ahumada Ortiz". Hermosillo, Sonora: Lecturas de la lechuza, viernes 30 de enero de 1998. 
Encinas, Johnson, L. “La Universidad de Sonora, Centro cultural del Noroeste”. Hermosillo Sonora: ponencia formulada por la Universidad de Sonora, entregada al Presidente de la República, Lic. Adolfo López Mateos. 20 de abril de 1958.

Méndez, Sainz, E. "Proyecto de universidad y de ciudad en Hermosillo de los cuarenta". Memoria XVII Simposio de Historia y Antropología de Sonora. Universidad de Sonora, Hermosillo, febrero de 1992.

\section{Periódicos.}

El Imparcial, El Sonorense, El pueblo. Archivo CIDOC: recopilación de notas sobre el movimiento en periódicos de la Ciudad de México. 